\section{Showpiece in transition}

\section{Zürich}

USUALLY, when one of an institute's researchers wins a Nobel prize, it is a time for some gentle back-slapping - the ultimate public relations boost for any research centre. And at first sight, the Swiss Federal Institute of Technology (ETH, or Eidgenössische Technische Hochschule) in Zürich seems no exception. At the entrance to the research tower housing the laboratory of Richard Ernst, this year's chemistry laureate (see Nature $\mathbf{3 5 3}, 689$; 24 October 1991), a handwritten placard, placed by his ETH colleagues, proclaims Ernst's Nobel success.

But the celebrations at ETH may be relatively short-lived, as its professors struggle to come to terms with the most radical overhaul of ETH's research enterprise in the institute's 136-year history. Over the past two years, the 300 professors and 2,500 scientific and technical staff responsible for research at ETH have been directed into 19 new research departments (biological sciences, chemistry, Earth sciences, forestry, pharmacy and the like). The new system has replaced a staggeringly complex array of more than 130 separate research units (mostly based on laboratories led by a handful of collaborating professors), each accountable directly to ETH's president.

At an institute of ETH's size, spending more than SFr200 million (about $\$ 136$ million) each year on research, the previous nineteenth-century organization was pushed beyond its limits, says Heinrich Ursprung, ETH president for 13 years until 1987, and now head of the Swiss agency that oversees federal government spending on basic science. According to
Ursprung, ETH is simply too large for the president to be personally responsible for its entire research programme. In 1987, a team of independent management consultants concluded that some delegation of power was essential if ETH was to retain its position as Switzerland's premier research centre.

But the particular scheme chosen by the board that governs ETH and its sister institute, the Swiss Federal Polytechnic in Lausanne, has met with widespread opposition from ETH's professors. Ernst is dismissive: "It's just nonsense." He believes the 19 departments have placed a layer of bureaucracy between the professors and the president that could undermine the very research excellence on which ETH's reputation is built. Rather than the most productive researchers being rewarded with proportionately more money for basic laboratory supplies and travel (as happened when the president controlled their budgets), Ernst fears that the new department heads will take a more evenhanded approach, with most dividing their funds more or less evenly among their professors.

The dissatisfaction of high-fliers such as Ernst with this egalitarian prospect is easy to understand, but, according to Peter Stössel, an assistant to ETH's vice-president for research, Ernst's opposition to the new structure is widely shared. Most ETH professors, it seems, jealously guarded their direct line of communication to the president's office ("a republic of kings" is how one ETH administrator describes the old organization), and now feel devalued by reporting instead to a mere head of department.
This resentment might recede given time, but there are other problems with the new structure that may force further changes. Restructuring ETH into departments seems an obvious development to researchers accustomed to the structure of a typical British or North American research university. But the 19 new research departments at ETH were created alongside an identical number of existing teaching divisions. These divisions are again organized by discipline, but because each is responsible for particular traditional degree course curricula taught to ETH's 11,000 students, their interests do not overlap exactly with those of the new research departments.

To an outsider, the decision to create a parallel structure for research management, rather than unifying ETH's organization for teaching and research, looks like a missed opportunity to reduce bureaucracy. Ex-president Ursprung agrees: in 1987 , he favoured the creation of 15 to 20 new departments responsible for both teaching and research. Nevertheless, he accepted the solution adopted by ETH's governing board because, he says, "I felt it was a step in the right direction."

Ursprung believes that too little power has so far been devolved from the ETH president. And Hans Bühlmann, Ursprung's successor as president until his return to mathematics research last year, says that perhaps half of the new research departments have taken a "waitand-see" approach, and have yet to take over full responsibility for their own research programmes.

More changes are likely - Jakob Nüesch, who joined ETH as president last year, from his post as head of research at the Swiss-based pharmaceuticals company Ciba-Geigy, agrees that some tinkering is

\title{
Swiss government plans to boost research
}

\section{Zürich}

THE Swiss federal government, long content to let Swiss-based industry pay for the vast majority of the scientific research carried out within the country's borders, now plans'to increase its spending on basic science by 16 per cent a year over the next four years. Last month, the lower house of the Swiss parliament approved a budget that will provide up to SFr2,109 million (about $£ 800$ million) for Swiss science from 1992 to 1995.

The new federal government science budget sets the maximum amount of money that will be made available over the next four years, and the parliament is free to spend less than the planning figures when it agrees on each year's level of public expenditure. But Swiss science officials are nonetheless pleased with their political paymasters' new-found discovery of the value of re- search. Peter Fricker, secretary general of the Swiss National Science Foundation (which is due to receive two-thirds of the four-year budget), describes the federal government's action as "a conscientious effort" to strengthen Swiss basic research.

In return for increasing its spending on science, the federal government is taking a greater role in defining the overall direction of Swiss research. The new planning budget includes more than SFr350 million for six new 'priority programmes' of strategic research, designed to underpin the national economy. Three of these (in biotechnology, informatics and the environment), will be run by the National Science Foundation. The others, in materials science, information technology and optics, are the responsibility of the two main research institutes funded directly by the federal government: the Federal Institute of Technology in Zürich and the Federal
Polytechnic in Lausanne. Fricker expects the science foundation's priority programmes to concentrate on funding university-based researchers, and says that experts from elsewhere will be called in to help with their planning.

The Swiss federal government's decision to boost its spending on science, at a time when science spending in several other European countries is stagnating in the face of economic difficulties, comes in response to a 1990 analysis from the Organization for Economic Cooperation and Development (OECD) showing that, while total Swiss spending on research and development (at around 3 per cent of the country's gross domestic product) was near the average for the developed world, the proportion coming from government was the lowest for all of the OECD countries.
Peter Aldhous 